\title{
Development of the Knowledge and Attitudes About Near-Death Experiences Scale (KANDES)
}

\author{
Laura Pace, PhD; Janice Miner Holden, EdD; \\ Sarah Blalock, PhD \\ University of North Texas \\ Ryan Holliman, $\mathrm{PhD}$ \\ Texas Woman's University \\ Robin K. Henson, PhD \\ University of North Texas
}

\begin{abstract}
The purpose of this study was to fill a need in the field of neardeath studies by developing an instrument to measure healthcare professionals' knowledge and attitudes about near-death experiences (NDEs) that would demonstrate acceptable psychometric properties. In consultation with a focus group of six NDE experts, we developed the 50-item Knowledge and Attitudes About Near-Death Experiences Scale (KANDES), including the 24-item KANDES-
\end{abstract}

\footnotetext{
Laura Pace, PhD, LPC-S, NCC, was a University of North Texas Counseling Program doctoral candidate at the time of the research described in this article. She is now in the private practice of counseling in Richardson, TX, specializing in eating disorders, trauma, and spirituality. Janice Miner Holden, EdD, LPC-S, LMFT, NCC, ACMHP, is professor in the Counseling Program and chair of the Department of Counseling and Higher Education at the University of North Texas in Denton, TX. Her primary research focus is near-death and other transpersonal experiences as they relate to counseling, development, and wellness. Sarah Blalock, PhD, LPC-S, RPT-S, CSC, was a University of North Texas Counseling Program doctoral candidate at the time of the research described in this article. She is now assistant professor in the Counseling Program at Texas State University in San Marcos, TX. Ryan Holliman, PhD, LPC-S, RPT-S is an assistant professor in the Family Sciences Department at Texas Woman's University. His primary research interests include child and adolescent counseling and assessment instrument development. Robin K. Henson, PhD, is a University Distinguished Teaching Professor of Educational Psychology in the Research, Measurement, and Statistics Program at the University of North Texas in Denton, TX. His primary research interests include applied statistics, measurement, and self-efficacy theory. Correspondence regarding this article should be sent to Dr. Pace at e-mail: laurajspace@gmail.com.
} 
Attitude subscale (KANDES-A) and the 26-item KANDES-Knowledge subscale (KANDES-K). A total of 256 adult participants completed the KANDES (49.6\% counseling students, $47.3 \%$ practicing counseling professionals, 3.9\% unspecified). Of these, the overwhelming majority of participants were female (80.5\%); $18.8 \%$ were aged $18-26$ years, $38.7 \%$ were $26-35,38.7 \%$ were over 35 , and $4.2 \%$ did not specify; and ethnicities were 79.2\% Caucasian, 8.2\% Latino, 7.4\% African American, and 5.2\% unspecified.

For the KANDES-A, exploratory factor analysis indicated four factors and yielded a factor solution that explained $54.87 \%$ of the variance, an acceptable amount of variance to substantiate construct validity. Regarding reliability, Cronbach's alpha and Pearson's $r$ for test-retest yielded acceptable results for the KANDES-A and its four factors and for the KANDES-K and its three domains: NDE Content, NDE Aftereffects, and Experiencer Characteristics. Interitem correlations further demonstrated acceptable reliability for the four factors and three domains. The KANDES now provides NDE researchers with an instrument to assess both existing knowledge and attitudes about NDEs and the effectiveness of interventions to improve those characteristics among healthcare and other professionals.

KEY WORDS: near-death experiences, healthcare professionals, attitudes, knowledge, assessment instrument development

Over 40 years of research reveals that of all the people who survive a close brush with death, approximately one in five reports a near-death experience (NDE; Zingrone \& Alvarado, 2009). An NDE is a typically lucid and real or hyper-real experience of one's consciousness functioning apart from the physical body, observing the material world and observing and interacting with transmaterial environments and entities, such as deceased loved ones and spiritual beings (Holden, 2009; Zingrone \& Alvarado, 2009). In the aftermath of the experience, experiencers (NDErs) manifest characteristic psychological, spiritual, physical, and interpersonal aftereffects whereby they often report feeling transformed (Holden, 2012; Noyes, Fenwick, Holden, \& Christian, 2009). They typically report that integrating these aftereffects into their subsequent lives is a difficult and isolating process (Furn, 1987; Holden 2012; Noyes et al., 2009). These challenges are exacerbated when they disclose their NDEs to confidants who respond with uncertainty, doubt, or even cynicism (Brumm, 2006; Holden, Kinsey, \& Moore, 2014).

Adverse responses to NDE disclosure can be especially harmful when the confidant is a health professional (Foster, James, \& Holden, 2009). Historically, health providers have viewed NDEs as hallucinations or even as evidence of psychological derangement (Greyson, 1983). These views and reactions reflect a negative attitude toward NDEs 
and NDErs that seems to derive from incomplete or inaccurate knowledge about the phenomenon and those who experience it. Despite the importance of this topic for thousands of NDErs' wellbeing, a review of the professional literature revealed only six published studies in English of health professionals' knowledge of and attitudes about NDEs: four involving medical health providers, three of nurses (Barnett, 1991; Bucher, Wimbush, Hardie, \& Hayes, 1997; Cunico, 2001) and one of physicians (Moore, 1994); one involving psychologists (Walker \& Russell, 1989); one involving clergy (Bechtel, Chen, Pierce, \& Walker, 1992); one involving a mixture of physicians, nurses, and pastoral healthcare providers (Goedhart, 2011); and none involving counselors or other health professionals (Foster et al., 2009).

A factor in this dearth of research has been the absence of an upto-date, psychometrically strong instrument with which researchers could assess health professionals' knowledge and attitudes about NDEs. In 1988, nurse Nina Thornburg published an instrument she called the Near-Death Phenomena Knowledge and Attitudes Questionnaire (KAQ). She consulted professionals in the fields of psychology, sociology, and medicine to construct the items of the instrument's three scales-a 23-item Knowledge scale, a 23-item Attitude toward Near-Death Phenomena scale, and a 20-item Attitude toward Patient Care scale-and to determine the content validity of the instrument's prompts. Thornburg administered the instrument to 20 registered nurses in various crisis-related units of a large hospital and found Cronbach's alphas of $.83, .84$, and .81 for scores on the respective scales (Thornburg, 1988, p. 227), reflecting acceptable internal consistency (cf. Henson, 2001). She conducted a factor analysis on her Attitude toward Near-Death Phenomena scale to evaluate construct validity and identified four factors for the obtained scores: (a) reporting NDEs, (b) factors influencing or affecting care, (c) psychological implications of NDEs, and (d) patient care activities surrounding NDEs.

In most published studies of knowledge and attitudes about NDEs, researchers either used or adapted Thornburg's instrument (Barnett, 1991; Bechtel et al., 1992; Bucher et al., 1997; Cunico, 2001; Moore, 1994; Walker \& Russell, 1989). In a recent study of Dutch healthcare professionals' general and care-specific attitudes toward NDEs, Sandra Goedhart (2011) found Thornburg's instrument to be dated and of questionable validity (p. 8). She developed a new instrument, and although she used consultation with experts to create the items, piloted the instrument, and found scores on the two scales of her instrument to be reliable, several factors render her instrument unusable 
for widespread research: She did not conduct factor analysis on her results, the instrument items are in Dutch, and the instrument addresses attitudes about but not knowledge of NDEs. Thus, the purpose of this study was to create a psychometrically acceptable, up-to-date instrument to assess healthcare professionals' knowledge of and attitudes regarding NDEs.

\section{Method}

In this section, we describe the several steps we took to develop the Knowledge and Attitudes About Near-Death Experiences Scale (KANDES). First, we discuss our process of item creation. Then, we present our process to establish validity and reliability evidence for scores on each of the KANDES's two subscales.

\section{Creation of Initial Instrument}

We designed the KANDES to be self-administered. Thus, results reflect respondents' self-reported responses to each item, which Nardi (2006) identified as an effective means of studying attitudes and opinions.

To construct the attitude subscale (KANDES-A), we followed the methods and procedures outlined by Abell, Springer, and Kamata (2009). To address the possibility that respondents might not be familiar with the contents of NDEs, we began with a vignette: a case example of an NDE - though not labeled as such. According to Abell et al. (2009), using vignettes in rapid assessment instrument development is one way to overcome the potential lack of participant experience with the primary focus of an instrument. Respondents were instructed to keep the vignette in mind as they responded to the items that followed.

We generated KANDES-A items based on co-author Holden's expertise in both mental healthcare and NDEs (Holden, Greyson, \& James, 2009). She found that potentially helpful or harmful healthcare professionals' (HPs') responses to clients'/patients' disclosures of NDEs seemed to reflect one or more of four factors: (a) label, whether or not, when clients/patients disclosed NDEs to an HP, the HP recognized and labeled the experiences as NDEs; (b) spiritual, whether the HP considered NDEs to be actually or potentially spiritually benevolent or malevolent; (c) diagnosis, whether the HP considered NDEs to be unrelated to or an indication of mental disorder; and (d) real, whether or not the HP considered NDEs might be objectively real rather than 
imaginary or hallucinatory. These factors were subsequently verified by NDErs themselves as differentiating whether they felt helped or harmed by the way they perceived HPs to have responded to their disclosures of their NDEs (Holden, Kinsey, \& Moore, 2014; Holden, Kinsey, Henson, \& Greyson, 2016).

KANDES-A items were statements pertaining to the vignette to which participants responded with a rating on a 7-point Likert-type scale ranging from completely agree to completely disagree with a midpoint option of unsure. Abell et al. (2009) asserted that using up to 7 points in a Likert-type scale can show slight differences among participants and increase scale sensitivity. The initial KANDES-A included 16 items-four for each category-half worded negatively and half positively to reduce agreement bias (Abell et al., 2009, p. 44). Items were scored such that higher scores indicated a more positive attitude toward NDEs.

At the start of the knowledge subscale (KANDES-K), respondents were instructed to respond to the items that followed without reference to the previous vignette. To develop KANDES-K items, co-author Pace drew from her own critical review of the NDE literature as well as from Holden's NDE expertise (Holden et al., 2009). We generated 10 items in each of two domains: NDE Content, common elements that NDErs encounter during their NDEs; and NDE Aftereffects, common post-NDE psychological, spiritual, physical, and social changes among NDErs (Holden, 2012; Holden et al., 2009). Once again, to reduce respondent agreement bias, we worded half of the items in each category positively and half negatively (Abell et al., 2009). Because items on a knowledge scale are criterion based rather than norm based, and each KANDES-K item was designed to be either completely true or completely false, participants responded to each item on a 7-point Likerttype scale ranging from completely true to completely false with a midpoint option of unsure. Items were scored such that higher scores reflected more accurate knowledge. Before proceeding, we received permission from the University of North Texas Institutional Review Board for the Use of Human Subjects to conduct her study.

\section{Focus Groups}

Using expert reviewers in instrument composition is central in establishing content and face validity (Fink, 2003; Gall, Gall, \& Borg, 2003; Granello, 2007). To determine content validity of the KANDES items, Pace conducted a focus group of experts in the field of near-death stud- 
ies who represented various professions within the healthcare field, including a psychiatrist, two professional nurses, and professional counselors. Because these individuals were located across the United States, Pace posted the initial KANDES on Qualtrics electronic survey program, asked each group member to respond, and then used conference calling to enable group discussion to seek to reach consensus on the scale.

For both the KANDES-A and -K, Pace provided members a format to rate each item as relevant (3), moderately relevant (2), or not relevant (1) to the subscale category or domain. In addition, for items on KANDES-K she asked focus group members to rate items as strongly (3), moderately (2), or not (1) corresponding to NDE research findings. She flagged an item that received a mean rating of 2 or less to specifically discuss during the focus group conference call. In addition, for each item on both subscales, she provided a feedback box where focus group members could make text comments.

After receiving the responses of all six experts comprising the focus group, Pace held a conference call with the five available experts. In discussing the KANDES-A, focus group members expressed some concern about the category real, suggesting it may be ambiguous due to the various definitions and interpretations of the word "real." They recommended separating this subscale into a real/truth category-whether NDErs were telling the truth about what they had experienced-and a dream/hallucination category - whether or not NDEs are or could be objectively real. Pace deleted three existing items and added three new items to the real/truth subcategory and three new items to the dream/ hallucination subcategory. Members also recommended that items specifically reflecting the helpful or hurtful nature of HPs' possible responses should be added to the KANDES-A. Therefore, she created the therapeutic subcategory and added four additional items.

In discussing the KANDES-K, focus group members recommended the addition of two domains: one to address characteristics of NDErs, and another to address differentiation of close brushes with deaththe circumstances in which NDEs sometimes occur such as car accidents or cardiac arrest episodes-from actual NDEs. In response, Pace created the Experiencer Characteristics domain by putting one existing item into it and creating three more, and she created the CloseBrush With Death domain by creating four new items.

Using Qualtrics, Pace submitted the modified KANDES to the focus group members. She included text entry boxes for focus group members' feedback and/or suggestions. Focus group members approved all 
of the items-24 KANDES-A and 26 KANDES-K-with a few minor wording modifications.

\section{Participant Selection and Data Collection}

Pilot study. Using the modified KANDES, Pace conducted a pilot study. Participants were individuals from the targeted sample for the main study: professional counselors (PCs) and student counselors (SCs). According to Pett, Lackey, and Sullivan (2003), a sample at least onetenth of the targeted sample size is sufficient for a pilot study. Based on Abell et al.'s (2009) specification of 200-300 total participants for instrument development, Pace recruited 25 participants for the pilot study. She recruited SCs by attending a class in the master's counseling program at the University of North Texas and asking students to participate; she recruited PCs through professional contacts who she knew were licensed, practicing, and not NDE professionals and who had professional email addresses available publicly through an Internet search of their names. Of the original 25 volunteers, 18 participants$8 \mathrm{SCs}$ and $10 \mathrm{PCs}$ - provided complete data sets.

Pilot participants completed the KANDES via Qualtrics online survey software. In addition to providing the instrument, Pace provided participants with a format to offer comments about the instrument and recommendations for improvement. Pilot participants also completed a demographics information questionnaire in which they reported their age, sex, ethnicity, and student or professional status.

Because the two KANDES subscales measure different latent variables, we conducted separate analyses on them. All quantitative data were analyzed using SPSS. To evaluate internal reliability of the KANDES, we calculated Cronbach's alphas (Cronbach, 1951; Henson, 2001; Walsh \& Betz, 2001). According to Nunnally and Bernstein (1994) and Shrout (1998), acceptable alpha statistics for non-clinical use are .60 or greater. Results were $\alpha=.865$ for the KANDES-A and $\alpha=.860$ for the KANDES-K scores. Based on acceptable coefficient alphas, we did not make changes to any KANDES-A or -K items prior to main study data collection.

In their text box responses, multiple participants stated that the seven response options on the KANDES-K seemed a bit unnecessary. According to Abell et al. (2009), 7-point response options for what actually constitutes a dichotomous (true/false) scale is usually unnecessary. Therefore, we reduced the KANDES-K responses from seven to five options. 
Main study. To achieve an appropriate sample size, Pace recruited study participants from various U.S. universities containing counselor education programs accredited by the Council for Accreditation of Counseling and Related Educational Programs (CACREP). She entered the counseling program names in a randomization program in Qualtrics and then selected the first 10 programs on the list-two from each of the five CACREP geographic regions-to contact for preliminary permission to distribute to their students and faculty her request to participate. Due to low returns from her initial request, she invited additional programs to participate-all chosen randomly through Qualtrics and representing all five CACREP regions-until she reached 250 participants.

All SC and some PC participants came from the recruitment emails to CACREP programs. Pace also recruited PC participants from two professional counseling organizations: the Association for Creativity in Counseling, from which she received permission to disseminate her request via email to members, and the Association for Spiritual, Ethical, and Religious Values in Counseling, the leadership of which forwarded her request to their members via email.

Participants were representative of the general counseling population of interest and were assumed to have neither specialized knowledge of NDEs nor affiliation with NDE-related organizations. A total of 256 respondents completed the KANDES-A, and 255 respondents completed the KANDES-K. Participants were $49.6 \%$ SCs, $47.3 \%$ PCs, and $3.9 \%$ unspecified. Their combined demographics were $80.5 \%$ female, $16.8 \%$ male, $2.7 \%$ unspecified; $18.8 \%$ aged $18-26,38.7 \%$ aged $26-35,38.7 \%$ over age 35 , and $4.2 \%$ unspecified; and $79.2 \%$ Caucasian, $8.2 \%$ Latino, $7.4 \%$ African American, and 5.2\% of other or unspecified ethnicity.

\section{Data Analysis}

Although four areas were expected in the KANDES-A, a limited amount of theory and history did not warrant a confirmatory factor analysis to examine construct and structural validity. Instead, we conducted an exploratory factor analysis (EFA) using the correlation matrix of association and the principal component analysis method of factor extraction (Henson \& Roberts, 2006). We determined how many factors to retain through a combination of three commonly used methods in instrument development: Kaiser-1 criterion of initial eigenvalues of at least 1, Catell's scree plot analysis of the bend in the graph of the eigenvalues, and parallel analysis (Turner, 1998) comparing 
the observed eigenvalues with random eigenvalues (Abell et al., 2009). Upon determining the number of factors, because the factors were assumed to be uncorrelated (Pett et al., 2003) and because of the effectiveness of orthogonal rotation in achieving simple factor structure and data reduction (Hair, Black, Babin, Anderson, \& Tatham, 2006), we analyzed items using the orthogonal varimax rotation (Abell et al., 2009, Kaiser, 1960). Our guideline for retaining items was having a factor pattern/structure coefficient of at least .4 on only one of the factors and that the item was interpretable on the factor with which it was associated (cf. Henson \& Roberts, 2006).

Regarding validity of the KANDES-K, because a knowledge scale is criterion based rather than norm based, we did not conduct factor analysis. Instead, we relied on criteria that emerged from a thorough review of the extensive research literature on, and from the feedback of experts in the field of near-death studies regarding, the three -K domains: the contents and aftereffects of NDEs and the characteristics of NDErs. This approach is appropriate in particular when the items assess a dichotomous phenomenon such as, in the $-\mathrm{K}$, the true/false nature of item content (DeVellis, 2012).

We used three methods to assess reliability of scores on both Attitude and Knowledge subscales. First, we calculated Cronbach's alpha for scores on the total subscale and for each factor or domain, using a criterion of at least .6 to indicate acceptable internal consistency for non-clinical use (Nunnally \& Bernstein, 1994; Shrout, 1998). Second, we calculated inter-item correlations for each factor or domain, using the criterion of acceptability that mean correlations fell within a range of .15 to .50 and that all correlations clustered closely around the mean value (Clark \& Watson, 1995). Third, we administered the KANDES to a subgroup of respondents from the total sample $(n=35)$ a second time 7-10 days after initial administration and calculated test-retest reliability (Pearson's $r$ ) between the initial and follow-up assessments for the total subscale and each factor or domain, using a criterion of at least .5 to indicate acceptable reliability (Landis \& Koch, 1977).

\section{Results}

\section{Attitude Subscale}

EFA yielded six factors with eigenvalues of at least 1 . Scree plot results showed one strong factor and potentially three additional factors prior to the plot line becoming quasi-horizontal. Parallel analysis indicated three factors with KANDES eigenvalues greater than random eigenvalues and a fourth factor in which the obtained KANDES eigenvalue 
was only .03 less than its random counterpart. Upon examining the items of the latter factor, because of the uniqueness and theoretical significance of the item theme, we decided to retain it as a factor. The item level factor analysis results, based on a four-factor solution using the orthogonal varimax rotation, appear in Table 1 . All items met cri-

Table 1 KANDES-A Factor Pattern/Structure Matrix Rotated to the Varimax Criterion

\begin{tabular}{|c|c|c|c|c|c|}
\hline \multirow[b]{2}{*}{ Item } & \multicolumn{4}{|c|}{ Factor } & \multirow[b]{2}{*}{$h^{2}$} \\
\hline & 1 & 2 & 3 & 4 & \\
\hline 10. Imaginary & .851 & .144 & .082 & .064 & .756 \\
\hline 11. Hallucination & .816 & .188 & .077 & .160 & .733 \\
\hline 8. Dream & .798 & .201 & .162 & .099 & .712 \\
\hline 9. Objective real & .794 & .168 & .048 & .146 & .682 \\
\hline 4. Benevolent & .642 & .103 & .075 & .221 & .477 \\
\hline 16. Not believe & .623 & .146 & .341 & .165 & .553 \\
\hline 24. Recognize NDE & .571 & .105 & .242 & .108 & .408 \\
\hline 6. Helpful & .546 & .059 & .261 & .282 & .449 \\
\hline 20. Avoid & .163 & .740 & .072 & .096 & .588 \\
\hline 21. Every opportunity & .138 & .729 & -.007 & .187 & .585 \\
\hline 22. Steer away & .181 & .667 & .203 & .182 & .552 \\
\hline 23. Talk more & .008 & .646 & .241 & -.058 & .479 \\
\hline 17. Truthful & .353 & .541 & .299 & .135 & .525 \\
\hline 19. Honest & .299 & .496 & .278 & .150 & .435 \\
\hline 14. Mental illness & .242 & .136 & .755 & .137 & .666 \\
\hline 12. Question health & .062 & .067 & .701 & .150 & .522 \\
\hline 18. Lying & .299 & .288 & .643 & .107 & .597 \\
\hline 13. Not doubt sanity & .156 & .213 & .593 & -.005 & .422 \\
\hline 5. Threatening & .054 & .125 & .511 & .366 & .413 \\
\hline 3. What to make & .258 & .154 & .058 & .795 & .726 \\
\hline 1. Surprised & .145 & .042 & .270 & .794 & .726 \\
\hline 2. Not uncommon & .247 & .169 & .044 & .652 & .516 \\
\hline 15. Normalcy & .177 & .180 & .418 & .536 & .526 \\
\hline Trace & 4.732 & 2.904 & 2.901 & 2.512 & \\
\hline$\%$ of variance & 20.574 & 12.627 & 12.612 & 10.922 & \\
\hline
\end{tabular}

Note. Trace = eigenvalues after rotation. \% of variance is post-rotation. $h^{2}=$ communality coefficient, represents the proportion of variance in an item that is reproduced by the factors. 
teria for inclusion except Item 7, which we eliminated: I would consider the experience to be evil or "of the devil." Examining all items by factor, we determined new factor labels: Factor 1, Real, Spiritually Beneficial Experience; Factor 2, Believe and Encourage to Talk; Factor 3, Mental Health Implications; and Factor 4, Recognizable Phenomenon.

Reliability analysis results appear in Table 2. The total KANDES-A and each factor demonstrated acceptable internal and test-retest consistency for their scores, and each factor demonstrated satisfactory inter-item consistency with its correlations.

\section{Knowledge Subscale}

Cronbach's alpha for scores on KANDES-K Domain 4, Close-Brush with Death, was .378, indicating low reliability (Nunnally \& Bernstein, 1994; Shrout, 1998). Therefore, we eliminated the three Domain 4 items from the instrument. Reliability results for scores on the KANDES-K total and three remaining domains appear in Table 3. The total KANDES-K and each domain demonstrated acceptable internal and test-retest consistency for their scores, and each of the three domains demonstrated satisfactory inter-item consistency with its correlations.

\section{Discussion}

The primary focus of this study was to develop an assessment instrument that yields acceptable psychometric properties for its scores, and the KANDES adheres to psychometric standards for new instru-

Table 2 KANDES-A Reliability Results

\begin{tabular}{lccccc} 
& \multicolumn{5}{c}{ Factor } \\
\cline { 2 - 7 } Type of analysis & $\mathbf{1}$ & $\mathbf{2}$ & $\mathbf{3}$ & $\mathbf{4}$ & Total \\
\hline Cronbach's alpha & .894 & .790 & .736 & .782 & .909
\end{tabular}

Inter-item correlation

\begin{tabular}{lccccc} 
Range & $.358-.788$ & $.296-.572$ & $.255-.583$ & $.403-.694$ & \\
Mean & .512 & .393 & .383 & .478 & \\
& & & & & \\
$\begin{array}{l}\text { Test-retest } \\
\text { correlation }\end{array}$ & .791 & .655 & .775 & .665 & .748 \\
\hline
\end{tabular}


Table 3 KANDES-K Reliability Results

\begin{tabular}{lcccc} 
& \multicolumn{4}{c}{ Domain } \\
\cline { 2 - 4 } Type of analysis & $\mathbf{1}$ & $\mathbf{2}$ & $\mathbf{3}$ & Total \\
\hline Cronbach's alpha & .816 & .817 & .631 & .908
\end{tabular}

Inter-item correlation

$\begin{array}{lccc}\text { Range } & .106-.553 & .074-.558 & .144-.550 \\ \text { Mean } & .321 & .328 & .299\end{array}$

Test-retest correlation

.791

.841

.775

.812

ment creation. Face and content validity were established through expert review, with focus group members agreeing that both the KANDES-A and -K accurately reflected the most current information arising from NDE research and that the KANDES-A accurately represented potential health professionals' reactions to or outlooks on patients'/clients' disclosure of NDEs. Validity was further substantiated through exploratory factor analysis of the KANDES-A, and evidence for reliability was established through internal consistency, inter-item correlations, and test-retest of both subscales. Collectively, these results provide support for using the KANDES in future research as an instrument that is theoretically relevant and can yield psychometrically sound scores for research purposes. Because evidence for the psychometric properties was confirmed for both the final 23item KANDES-A and 23-item KANDES-K, which measure different latent variables related to NDEs, the subscales can be used either together or separately.

Regarding generalizability of the instrument, the sample for this study consisted of master's counseling students and practicing counseling professionals. Both groups were represented almost equally: 49\% and $47 \%$ respectively. Thus, the KANDES can be used with confidence with counseling professionals. However, we designed the KANDES for use with a wide range of health professionals, and we hope that future investigators will confirm its use with these populations.

Although not the primary focus of this study, the distribution data from participants' responses may be of interest to readers. Results from the main study indicated that many professional counselors' and 
counseling students' attitudes lean toward positive and their knowledge leans toward accurate. These preliminary results also indicated some negative attitudes and inaccurate knowledge, suggesting that targeted education of counseling professionals and students is warranted and needed for counselors to work competently and ethically with NDEr clients.

This study has several limitations. Because no comparable instrument existed with which to compare results, we were unable to establish criterion validity for the KANDES scores. Furthermore, the sample employed, although adequate in size and in geographic diversity, was limited with regard to ethnic diversity. Finally, the validity of the preliminary results of the KANDES is inherently limited by the nature of the voluntary sample used. Specifically, members of the organizations invited to participate-one focusing on creativity in counseling and another on spiritual/religious issues in counseling-may have more positive attitudes and relatively greater knowledge about NDEs than typical student and practicing counselors. Future studies involving more representative samples will elucidate whether these factors affected our results.

We have several recommendations for future research. In addition to extending administration to a wider sample of counseling professionals and to other HPs, one possibility is to modify the KANDES by removing the "unsure" response option; forcing respondents to choose an answer might improve psychometric properties (Mondak, 2001). Future researchers also could supplement the factor analysis data from this study by conducting confirmatory factor analysis on the KANDES-A with new samples. One final area of future study could be an analysis of the relationship between participants' scores on the KANDES-A and the KANDES-K to examine whether attitudes improve as knowledge increases, as well as beginning the development of a nomological network of how these subscales should or should not be related with other constructs in the literature.

The authors hope that future researchers will find the KANDES-A and KANDES-K useful in their research on professionals' existing knowledge of and attitudes toward NDEs and on the effectiveness of interventions to improve these phenomena. Researchers may access the KANDES free of charge at http://www.coe.unt.edu/sites/default/ files/22/Art_16_01_03_Pace_et_al_KANDES_Items_and_Scoring .docx. 


\section{References}

Abell, N., Springer, D. W., \& Kamata, A. (2009). Developing and assessing rapid assessment instruments. Oxford, England, UK: Oxford University Press.

Barnett, L. (1991). Hospice nurses' knowledge and attitudes toward the neardeath experience. Journal of Near-Death Studies, 9(4), 225-232. doi:10.17514/ jnds-1991-9-4-p225-232

Bechtel, L. J., Chen, A., Pierce, R. A., \& Walker, B. A. (1992). Assessment of clergy knowledge and attitudes toward near-death experiences. Journal of NearDeath Studies, 10(3), 161-170. doi:10.17514/jnds-1992-10-3-p161-170

Brumm, K. (2006). A study of near-death experiences and coping with stress. Journal of Near-Death Studies, 24(3), 153-173. doi:10.17514/jnds-2006-24-3p153-173

Bucher, L., Wimbush, F. B., Hardie, T., \& Hayes, E. R. (1997). Near death experiences: Critical care nurses' attitudes and interventions. Dimensions of Critical Care Nursing, 16(4), 194-201. doi:10.1097/00003465-199707000-00003

Clark, L. A., \& Watson, D. (1995). Constructing validity: Basic issues in objective scale development. Psychological Assessment, 7(3), 309-319. doi:10.1037/ 1040-3590.7.3.309

Cronbach, L. J. (1951). Coefficient alpha and the internal structure of tests. Psychometrika, 16(3): 297-334. doi:10.1007\bf02310555

Cunico, L. (2001). Knowledge and attitudes of hospital nurses in Italy related to near-death experiences. Journal of Near-Death Studies, 20(1), 37-50. doi:10.17514/jnds-2001-20-1-p37-50.

DeVellis, R. F. (2012). Scale development: Theory and applications (3rd ed.). Los Angeles, CA: Sage.

Fink, A. (2003). How to ask survey questions (2nd ed.). Thousand Oaks, CA: Sage.

Foster, R., James, D., \& Holden, J. M. (2009). Practical applications of research on near-death experiences. In J. M. Holden, B. Greyson, \& D. James (Eds.), The handbook of near-death experiences: Thirty years of investigation (pp. 235258). Santa Barbara, CA: Praeger/ABC-CLIO.

Furn, B. G. (1987). Adjustment and the near-death experience: A conceptual and therapeutic model. Journal of Near-Death Studies, 6(1), 4-19. doi:10.1007/ bf01073261

Gall, M. D., Gall, J. P., \& Borg, W. R. (2003). Educational research: An introduction (7th ed.). Boston, MA: Pearson Education.

Goedhart, S. (2011). Exploring general and care-specific attitudes of Dutch health care professionals towards the near-death experience. Unpublished master's dissertation, University of Amsterdam. Retrieved from http://r.search .yahoo.com/_ylt=A0LEVjKHQX1XeNAAgZ8nnIlQ;_ylu=X3oDMTEybmJ1ZW 80BGNvbG8DYmYxBHBvcwM0BHZ0aWQDQjIwMDNfMQRzZWMDc3I-/ $\mathrm{RV}=2 / \mathrm{RE}=1467855367 / \mathrm{RO}=10 / \mathrm{RU}=\mathrm{http} \% 3 \mathrm{a} \% 2 \mathrm{f} \% 2$ fdare.uva.nl\%2fdocument\%2f226787/RK=0/RS=Ka1.WFRtk9bEkhCNmfuedegLNzk-

Granello, H. D. (2007). Publishing quantitative manuscripts in Counselor Education and Supervision: General guidelines and expectations. Counselor Education and Supervision, 47(2), 66-75. doi:10.1002/j.1556-6978.2007.tb00039.x

Greyson, B. (1983). Near-death experiences and personal values. American Journal of Psychiatry, 140(5), 618-620. doi:10.1176/ajp.140.5.618 
Hair, J. F., Black, W. C., Babin, B. J., Anderson, R. E., and Tatham, R. L. (2006). Multivariate data analysis (6th ed.). Upper Saddle River, NJ: Prentice Hall.

Henson, R. K. (2001). Understanding internal consistency reliability estimates: A conceptual primer on coefficient alpha. Measurement and Evaluation in Counseling and Development, 34, 177-189.

Henson, R. K., \& Roberts, J. K. (2006). Use of exploratory factor analysis in published research: Common errors and some comment on improved practice. Educational and Psychological Measurement, 66, 393-416. doi:10.1177/ 0013164405282485

Holden, J. M. (2009). Veridical perception in near-death experiences. In J. M. Holden, B. Greyson, \& D. James (Eds.), The handbook of near-death experiences: Thirty years of investigation (pp. 185-211). Santa Barbara, CA: Praeger/ ABC-CLIO.

Holden, J. M. (2012). After-math: Counting the aftereffects of potentially spiritually transformative experiences. Journal of Near-Death Studies, 31(2), 6578. doi:10.17514/jnds-2012-31-2-p65-78

Holden, J. M., Greyson, B., \& James, D. (Eds.). (2009). The handbook of neardeath experiences: Thirty years of investigation. Santa Barbara, CA: Praeger/ ABC-CLIO.

Holden, J. M., Kinsey, L., Henson, R., \& Greyson, B. (Under review). Development of the Near-Death Experiencers' Experiences of Disclosure Scale (NEEDS).

Holden, J. M., Kinsey, L., \& Moore, T. R. (2014). Disclosing near-death experiences to professional healthcare providers and non-professionals. Spirituality in Clinical Practice, 1(4), 278-287. doi:10.1037/scp0000039

Kaiser, H. (1960). The application of electronic computers to factor analysis. Educational and Psychological Measurement, 20, 141-151. doi:10.1177/ 001316446002000116

Landis, J. R., \& Koch, G. C. (1977). The measurement of observer agreement for categorical data. Biometrics, 33(1), 159-174. doi:10.2307/2529310

Mondak, J. J. (2001). Developing valid knowledge scales. American Journal of Political Science, 45(1), 224-238. doi:10.2307/2669369

Moore, L. H. (1994). An assessment of physicians' knowledge of and attitudes toward the near-death experience. Journal of Near-Death Studies, 13(2), 91102. doi:10.17514/jnds-1994-13-2-p91-102.

Nardi, P. M. (2006). Doing survey research: A guide to quantitative methods (2nd ed.). Boston, MA: Pearson Education.

Noyes, R., Fenwick, P., Holden, J. M., \& Christian, S. R. (2009). Aftereffects of pleasurable western adult near-death experiences. In J. M. Holden, B. Greyson, \& D. James (Eds.), The handbook of near-death experiences: Thirty years of investigation (pp. 41-62). Santa Barbara, CA: Praeger/ABC-CLIO.

Nunnally, J., \& Bernstein, I. (1994). Psychometric theory (3rd ed.). New York, NY: McGraw-Hill.

Pett, M., Lackey, N., \& Sullivan, J. (2003). Making sense of factor analysis: The use of factor analysis for instrument development in health care research. Thousand Oaks, CA: Sage.

Shrout, P. E. (1998). Measurement reliability and agreement in psychiatry. Statistical Methods in Medical Research, 7, 301-317. doi:10.1191/ 096228098672090967 
Thornburg, N. R. (1988). Development of the near-death phenomena knowledge and attitudes questionnaire. Journal of Near-Death Studies, 6(4), 223-239. doi:10.17514/jnds-1988-6-4-p223-239

Turner, N. E. (1998). The effect of common variance and structure pattern on random data eigenvalues: Implications for the accuracy of parallel analysis. Educational and Psychological Measurement, 58, 541-568. doi:10.1177/00131 64498058004001

Walker, B. A., \& Russell, R. D. (1989). Assessing psychologists' knowledge and attitudes toward near-death phenomena. Journal of Near-Death Studies, 8(2), 103-110. doi:10.17514/jnds-1989-8-2-p103-110

Walsh, W. B., \& Betz, N. E. (2001). Tests and assessments (4th ed). Upper Saddle River, NJ: Prentice Hall.

Zingrone, N. L., \& Alvarado, C. S. (2009). Pleasurable Western adult near-death experiences: Features, circumstances, and incidence. In J. M. Holden, B. Greyson, \& D. James (Eds.), The handbook of near-death experiences: Thirty years of investigation (pp. 17-40). Santa Barbara, CA: Praeger/ABC-CLIO. 